www.juridicas.unam.mx

\title{
CORTE INTERAMERICANA DE DERECHOS HUMANOS. CASO RADILLA PACHECO VS. MÉXICO. SENTENCIA DEL 23 DE NOVIEMBRE DE 2009 (EXCEPCIONES PRELIMINARES, FONDO, REPARACIONES Y COSTAS)* INTER-AMERICAN COURT OF HUMAN RIGHTS. RADILLA PACHECO VS. MEXICO CASE. JUDGMENT OF 23 NOVEMBER 2009 (EXCEPTIONS, MERITS, REPARATIONS AND COSTS)
}

\section{Alonso GóMEZ-Robledo VerdUZCO**}

RESUMEN: El autor nos presenta un análisis de las excepciones preliminares, el fondo y las reparaciones del Caso Radilla Pacheco vs. México llevado ante la Corte Interamericana de Derechos Humanos, cuya sentencia fue publicada el 23 de noviembre de 2009. En cada uno de los apartados, el autor expone los argumentos que el Representante del Estado Mexicano presentó ante la Corte Interamericana de Derechos Humanos, la no admisión de los mismos y los argumentos que la propia Corte presentó para refutarlos. Por último, en anexo, se presenta el texto de la sentencia.

Palabras clave: Corte Interamericana de Derechos Humanos, Desaparición Forzada de Personas, Responsabilidad Internacional, Convención Americana de Derechos Humanos, Convención Interamericana sobre Desaparición Forzada

ABSTRACT: The author presents an analysis of the Exceptions, Merits and Reparations regarding the Radilla Pacheco vs. Mexico case, brought before the Inter-American Court of Human Rights, whose judgment was published on November 23, 2009. In each of the sections, the author shows the arguments that the Representative of Mexico submitted to the Inter-American Court of Human Rights, the non-acceptance of them and the arguments that the Court itself had to refute them. Finally, in the annex, is the text of the judgment. Descriptors: Inter-American Court of Human Rights, Forced Disappearance of Persons, International Responsibility, Inter-American Convention on Human Rights, Inter-American Convention on Forced Disappearance of Persons.

RÉSUMÉ: L'auteur présente une analyse des exceptions, du fond et des réparations concernant dans le cas Radilla Pacheco vs Mexique, lequel a été porté devant la Cour Interaméricaine des Droits de L'homme, dont la sentence a été publiée le 23 Novembre 2009. Dans chacune des sections, l'auteur montre les arguments que le représentant du Mexique a présentés à la Cour interaméricaine des Droits de L'homme, la non-acceptation de ceux et les arguments que la même Cour a présentés pour les réfuter. Enfin, dans l'annexe est le texte de la sentence.

* Artículo recibido el 13 de agosto de 2010 y aceptado para su publicación el 3 de septiembre de 2010.

** Doctor en Ciencia Política por el Instituto de Altos Estudios Internacionales de Ginebra (Suiza); investigador en el Instituto de Investigaciones Jurídicas de la UNAM. 
La justicia entraña — siguiendo a Radbruch una tensión incansable: su esencia es la igualdad; reviste, por tanto, la forma de lo general y aspira siempre, sin embargo, a tener en cuenta el caso concreto y al individuo concreto, en su individualidad

Antonio Gómez Robledo, Meditación sobre la justicia

Sumario: I. Caso Radilla Pacheco vs. Estados Unidos Mexicanos. Hechos. II. Introducción de la causa. III. Excepciones preliminares. IV. Segunda excepción preliminar. V. Tercera excepción preliminar. VI. Cuarta excepción preliminar. VII. Competencia. VIII. Reconocimiento parcial de responsabilidad internacional. IX. Capítulo de pruebas. X. Sobre la desaparición forzada de Rosendo Radilla Pacheco. XI. Detención y posterior desaparición. XII. Derechos de acceso a la justicia y la obligación de realizar investigaciones efectivas. XIII. El principio de efectividad en las investigaciones. XIV. Tipificación del delito. XV. Actuación en la jurisdicción militar. XVI. La esfera de la justicia castrense "vis-â-vis" la Convención Interamericana sobre Desaparición Forzada. XVII. Reserva de México. XVIII. Tipificación del delito de desaparición forzada de personas. XIX. Conclusiones. XX. Anexo.

\section{Caso Radilla Pacheco vs. Estados Unidos Mexicanos. HECHOS}

Los hechos del presente caso se refieren a la presunta desaparición forzada del señor Rosendo Radilla Pacheco, que habría tenido lugar desde el 25 de agosto de 1974, a manos de efectivos del Ejército del estado de Guerrero, México.

De acuerdo a la Comisión Interamericana, las alegadas violaciones derivadas de este hecho, "se prolongan hasta la fecha por cuanto el Estado mexicano no ha establecido el paradero de la [presunta] víctima ni se han encontrado sus restos. A más de 33 años de los hechos, existe total impu- 
nidad ya que el Estado no ha sancionado penalmente a los responsables, ni ha asegurado a los familiares una adecuada reparación". ${ }^{1}$

\section{INTRODUCCIÓN DE LA CAUSA}

El Estado mexicano interpuso ante la Corte Interamericana de Derechos Humanos, cuatro excepciones preliminares:

I) Incompetencia ratione temporis debido a la fecha de depósito de su instrumento de adhesión a la Convención Americana.

II) Incompetencia ratione temporis para aplicar la Convención Interamericana sobre Desaparición Forzada de Personas (CIDFP).

III) Incompetencia ratione materiae para utilizar la Carta de la Organización de Estados Americanos, como fundamentos para conocer del caso.

$I V)$ Incompetencia ratione temporis para conocer de presuntas violaciones al artículo 4o. (derecho a la vida) y 5o. (derecho a la integridad personal) de la Convención Americana, en perjuicio del señor Rosendo Radilla Pacheco.

\section{EXCEPCIONES PRELIMINARES}

En cuanto a la primera excepción preliminar el Estado mexicano, señaló que la Corte carecía de competencia, ratione temporis para conocer sobre los méritos del caso, ya que había firmado su instrumento de adhesión a la Convención Americana el 2 de mayo de 1981, depositando el mismo ante la Secretaría de la OEA el 24 de marzo de 1981. "Así, aún ante una desaparición, la Corte Interamericana no tiene competencia para conocer de actos jurídicamente irrelevantes, independientemente de que éstos continúen una vez que se ratifique la Convención Americana" (párr. 15).

1 El juez Sergio García Ramírez presentó una inhibitoria para participar en el presente caso en su "calidad de nacional del Estado demandado". La Corte comunicó a México de la referida excusa y le consultó acerca de su prerrogativa de nombrar un juez ad hoc, a lo cual el Estado mexicano contestó que no llevaría a cabo nombramiento alguno de juez o jueza ad hoc, de acuerdo al artículo 55 de la Convención Americana sobre Derechos Humanos. 
Al respecto la Corte señaló que debían distinguirse entre actos instantáneos y actos de carácter continuo o permanente. Estos últimos se extienden durante todo el tiempo en el cual el hecho continúa y se mantiene su falta de conformidad con la obligación internacional.

Dentro de la categoría de actos continuos o permanentes se encuadra la desaparición forzada de personas, cuyo carácter contínuo ha sido reconocido reiteradamente por el derecho internacional de los derechos humanos, "en el cual el acto de desaparición y su ejecución se inician con la privación de la libertad de la persona y la subsiguiente falta de información sobre su destino, y permanece hasta en tanto no se conozca el paradero de la persona desaparecida y los hechos no se hayan esclarecido" (par. 23).

La Corte va a desestimar la primera excepción preliminar ya que considera que en casos como el presente, le es aplicable a México las obligaciones de la Convención a aquellos hechos

que constituyan violaciones de carácter continuo o permanente, es decir, a los que tuvieron lugar antes de la entrada en vigor del tratado y persisten aún después de esa fecha puesto que ellas se siguen cometiendo. Sostener lo contrario equivaldría a privar de su efecto útil al tratado mismo y a la garantía de protección que establece, con consecuencias negativas para las presuntas víctimas en el ejercicio de su derecho de acceso a la justicia (par. 24). ${ }^{2}$

\section{SEGUNDA EXCEPCIÓN PRELIMINAR}

Por lo que respecta a la segunda excepción preliminar relativa a la competencia ratione temporis para conocer de presuntas violaciones a la "Convención Interamericana sobre Desaparición Forzada de Personas" México al ratificar dicha Convención el 9 de abril de 2002, realizó la siguiente declaración interpretativa":

2 En el mismo sentido veáse el Caso Velásquez Rodríguez vs. Honduras. 29/VII/1988: "La desaparición forzada de seres humanos constituye una violación múltiple y continuada de numerosos derechos...", párrafo 155. De la misma suerte la Corte de Estrasburgo ha reconocido el carácter continuo o permanente de la desaparición forzada. Cfr. Case of Loizidou vs. Tuykey. Judgment of 18 december 1996, párrs. 35 y 41 
Con fundamento en el artículo 14 de la Constitución Política de los E.U.M. ... se entenderá que las disposiciones de dicha Convención se aplicarán a los hechos que constituyan desaparición forzada de personas, se ordenen, ejecutan o cometan con posterioridad a la entrada en vigor de la presente Convención.

La Corte va a observar que del sentido corriente de los términos de la Declaración,

se desprende claramente que las disposiciones de tal instrumento son aplicables a hechos que se ejecuten o cometan con posterioridad a su entrada en vigor. A la luz del artículo 31 de la Convención de Viena de 1969 este Tribunal ha afirmado que el "sentido corriente" de los términos no puede ser una regla por sí misma sino que debe involucrarse dentro del contexto, y en especial dentro del objeto y fin del tratado... El "sentido corriente de los términos" debe analizarse como parte de un todo cuyo significado $\mathrm{y}$ alcance debe fijarse en función del sistema jurídico al cual pertenece (parrs. 28 y 30 ).

La Corte va a desestimar esta segunda excepción preliminar, en virtud de que la desaparición forzada del señor Radilla Pacheco continúa ejecutándose y por lo mismo la eventual aplicación de la "Convención Interamericana sobre Desaparición Forzada de Personas" (C.I.D.F.P) al caso sub iudice se encuentra dentro de la competencia temporal de la Corte (párrs. $31-32-37)^{3}$

\section{TERCERA EXCEPCIÓN PRELIMINAR}

En lo tocante en la tercera excepción preliminar interpuesta por México, en el sentido de que la Corte Interamericana carecía de competencia para utilizar la "Carta de la Organización de Estados Americanos", suscrita en Bogotá en 1948, como fundamento para conocer del presente

3 La Corte desestimó igualmente el alegato de México para conocer de la reserva al artículo IX de la CIDFP, relativa a la jurisdicción penal militar, recordando que en jurisprudencia reiterada se ha asentado "su jurisdicción plena sobre todas las cuestiones relativas a un caso sometido a su conocimiento, incluso sobre los presupuestos procesables en los que se funda la posibilidad de que ejerza su competencia" (párr. 34).

Por lo demás la Suprema Corte de Justicia, adoptó el criterio de los tribunales de derechos humanos, en el sentido de considerar la desaparición forzada, como "delito de carácter permanente o continuo". Tesis P/J. 49/2004, Gaceta XX, Novena Época, julio de 2004. 
caso, los representantes de las víctimas manifestaron no haber solicitado a la Corte declarar violación alguna respecto a la Carta de la OEA, sino simplemente habían requerido que dicho instrumento internacional fuese tomado en cuenta para la interpretación y determinación del alcance de las obligaciones que tienen los Estados al firmar y ratificar la Convención Americana sobre Derechos Humanos.

Para la Corte, la manifestación anterior por parte de los representantes deja muy en claro "que no existe en este punto controversia con lo que señala el Estado", y por ende la excepción preliminar interpuesta carece de objeto y debe ser desestimada. ${ }^{4}$

\section{CUARTA EXCEPCIÓN PRELIMINAR}

Por último y en referencia a la cuarta excepción preliminar interpuesta por México a fin de que la Corte Interamericana se declarase incompetente ratione temporis, para conocer de presuntas violaciones a los derechos a la vida y a la integridad personal, la Corte va a indicar que esta última excepción se fundamenta en la presunción conforme a la cual una persona desparecida, "se tiene como muerta cuando haya transcurrido un tiempo considerable, sin que se tenga noticias de su paradero o de la localización de sus restos" (párr. 44).

La presunción de muerte invocada por México, obviamente sólo puede tener carácter iuris tantum, y la Corte, con todo cuidado va a añadir que incluso una presunción de este tipo debe al menos poseer los siguientes elementos para que pueda configurarse como tal:

a) Debe existir un hecho o estado de cosas.

b) Debe establecerse la inexistencia de pruebas que permitan razonablemente inferir que dicho estado de cosas no es tal.

4 En la Opinión Consultiva sobre la "Interpretación de la Declaración Americana de los Derechos y deberes del Hombre en el marco del artículo 64 de la Convención Americana sobre Derechos Humanos", la Corte sostuvo que "teniendo en cuenta que la Carta de la OEA y la Convención Americana son tratados respecto de los cuales la Corte puede ejercer su competencia consultiva... ésta puede interpretar la Declaración Americana... en el marco y dentro de los límites de su competencia, cuando ello sea necesario al interpretar tales instrumentos". OC-10/89 del 14 de julio de 1989. Serie A, número 10, en García Ramírez, Sergio (coord.), La jurisprudencia de la Corte Interamericana de Derechos Humanos, vol. I, UNAM, Instituto de Investigaciones Jurídicas, p. 992, párrafo 44. 
c) Debe existir una regla de presunción respecto al hecho o estado de cosas.

d) Debe establecerse la conclusión de la presunción a la que se puede llegar luego de dicho análisis.

De igual forma, la Corte observa que, por lo general las reglas de presunción, invierten la carga de la prueba y en este sentido, subraya la Corte, sería de todo punto inadmisible - como era la intención del Estado"que la parte sobre quien recae la carga de desvirtuar la presunción haga uso de la misma a fin de excluir o limitar, anticipadamente mediante una excepción preliminar, la competencia del Tribunal... de lo contrario, el Estado estaría usando la presunción de muerte para invertir nuevamente la carga de la prueba" (párrs. 46-47-48).

Por lo expuesto y motivado, la Corte Interamericana, con toda lucidez, desestimó igualmente esta cuarta y última excepción preliminar, realizando con ello su competencia para conocer del fondo de la litis. $^{5}$

5 La presunción ha podido ser definida en Derecho Internacional general, como un medio de prueba consistente en inferir de ciertas circunstancias, la posible veracidad de un alegato en un proceso; incluso podría llegar a tener carácter de pleno derecho, pero a condición de que la presunción no deje lugar a ningún tipo de duda razonable.

Cuando en la práctica las presunciones y los indicios son tratados indistintamente, es porque la llamada "prueba indiciaria" está implícta en el sistema de la "sana crítica" que es precisamente su criterio rector. Veáse Dictionnaire de la terminilogie du droit international, París, Union Académique International, Sirey, 1960.

Por lo que concierne al "efecto útil" de los tratados y al "objeto y fin" de los mismos, la Corte Interamericana tuvo razón sobrada para analizarlas como lo hizo en las otras excepciones preliminares. Así el eminente Juez Charles de Visscher en su Opinión Disidente de 1950, sostuvo que era una regla de interpretación bien reconocida que las cláusulas de un tratado, deberían de ser no sólamente contempladas en su conjunto, sino también el que deberían interpretarse de manera a evitar, tanto como fuese posible, el privar a ninguna de ellas de su efecto útil en beneficio de otras. (C.I.J.Recueil 1950. p 187)

En tanto que la noción del "objeto fin" referente a un tratado de derechos humanos, sólamente puede tener un verdadero sentido - L. Lijnzaad-, si se realiza un serio análisis a fin de hacer operacional su contenido, siendo necesario por ello mismo, el determinar el contenido substantivo de la regla.

El profesor Paul Guggenhein, siguiendo el pensamiento del antiguo Juez Dionisio Anzilotti, ha subrayado que no podía entender como podría ser posible sustentar que un artículo cualquiera de una Convención, fuera una disposición "clara", si antes no se había determinado el objeto y fin del tratado, ya que es sólamente en dicho tratado y en relación expresa de dicho tratado, que el artículo o disposición de que se trata, asume su verdadero significado. Veáse Gómez-Robledo Verduzco, Alonso, Derechos humanos en el Sistema 


\section{COMPETENCIA}

La Corte Interamericana como todo órgano jurisdiccional, posee el poder inherente a sus atribuciones para determinar el alcance de su propia competencia, i.e., posee la compétence de la compétence.

En el caso presente, la Corte tiene una competencia expresa para conocer de la controversia, en virtud de que México es Estado parte de la Convención Americana desde el 24 de marzo de 1981 y reconoció la competencia contenciosa de la Corte el 16 de diciembre de 1988, así como por haber ratificado la Convención Interamericana sobre Desaparición Forzada de Personas, a partir del 9 de abril de 2002.

\section{RECONOCIMIENTO PARCIAL \\ DE RESPONSABILIDAD INTERNACIONAL}

En principio, el Estado mexicano va a reconocer una responsabilidad internacional en razón de que el señor Rosendo Radilla Pacheco, "fue privado ilegal y arbitrariamente de su libertad por un funcionario público", "incurrió en una demora injustificada en las investigaciones por la desaparición, localización e identificación de los probables responsables de los hechos delictivos y no garantizando a los peticionarios que su derecho al debido proceso sea garantizado rápidamente".

Pero curiosamente el Estado mexicano, una vez que parece reconocer una muy limitada responsabilidad, de inmediato se apresura a pedirle a la Corte que tome en cuenta que la "investigación y sanción de dichos hechos" se tornó más difícil por no haber sido denunciados oportunamente y que si bien "admite una demora injustificada", al mismo tiempo debe tomarse en cuenta la "complejidad del caso" y la "dificultad que implica una investigación de un caso que ocurrió largo tiempo atrás” (párrs. 52-53).

Además el Estado advierte que si bien pudo configurarse una denegación de justicia" ésta no se generó por negligencia o por impunidad, sino en todo caso, porque al Estado no le ha sido "posible localizar los restos

Interamericano, México, Porrúa, 2000, pp. 74-76 y 100-107; véase Guggenhein, Paul, Traité de droit internacional public, 2a. ed., t. I, Genéve, Librairie de L’Université, Gerorg, pp. 245-266.

Véase Anzilotti, Dionisio, Corso di diritto internazionale. Volumen primo, Padova, Cedam, 1964, pp 98-103. 
óseos de Radilla Pacheco o establecer su paradero", y de esta suerte México va a controvertir expresamente la "alegada impunidad, ya que la investigación continua" y la Corte debería, dice el Estado, "declararse incompetente para analizar el contexto circunstancial del caso sub iudic" (sic).

La Corte, como en otros casos, destaca que todo proceso ante la misma, se refiere a la tutela de los derechos humanos, cuestión de órden público internacional, y por lo tanto los actos de allanamiento, se deben confrontar con la gravedad de las violaciones, las exigencias de la justicia y las circunstancias particulares del caso concreto ( $C f r$. Caso Kawas Fernández. Sentencia del 3/IV/09, serie C, núm. 196. párrs. 23-24).

De cualquier forma y pese al aparente subterfugio procedimental del Estado mexicano respecto al allanamiento parcial de responsabilidad, "el Tribunal decide aceptar el reconocimiento formulado por el Estado y calificarlo como una admisión parcial de hechos y allanamiento parcial a las pretensiones de derecho contenidos en la demanda..." (párr. 63).

\section{CAPÍtUlo DE PRUEBAS}

La Corte procede a valorar y examinar los elementos probatorios documentales, así como las declaraciones rendidas mediante affidávit y en audiencia pública, así como las pruebas solicitadas para mejor resolver, dentro del sistema y principios de la sana crítica. (Cfr. Caso de la "Panel Blanca" vs. Guatemala, fondo, sentencia 8/III/98, serie C, núm. 37, párr. 76).

Aquí es pertinente realzar que la Presidencia de la Corte solicitó al Estado la remisión de una copia de una Averiguación Previa (SIEDF/ C.G.I/454/07) relativa a la presunta desaparición al acervo probatorio.

Sin embargo el Estado se negó a presentar dicho documento, aduciendo que "en caso que la Corte... corriera traslado de la averiguación previa referida a la Comisión Interamericana... y a los peticionarios, se afectaría el correcto desarrollo de la procuración de justicia..." (parr. 88).

Ante esta respuesta, no justificada y muy poco diplomática por parte del representante del Estado, la Corte sostuvo que, "es el Estado quien tiene el control de los medios para aclarar hechos ocurridos dentro de su territorio y, por ello su defensa no puede descansar sobre la imposibilidad del demandante de allegar pruebas, que en muchos casos, no pueden obtenerse sin la cooperación de las autoridades estatales". ${ }^{6}$

6 Esto ha sido asentado en jurisprudencia anterior, como fue el Caso Ríos y otros vs. Venezuela, excepciones preliminares, fondo, reparaciones y costas, sentencia del 28 de 
Evidentemente ante esta negativa por parte del Estado, la Corte va a tener como establecidos los hechos presentados por la Comisión Interamericana, ya que corresponde a la Corte y solamente a ella "determinar el quantum necesario de prueba en cada caso concreto" (párr. 92).

\section{SOBRE LA DESAPARICIÓN FORZADA DE ROSENDO RADILLA PACHECO}

En su contestación a la demanda, el Estado mexicano sostuvo que la Corte "se encontraba impedida para conocer de las circunstancias sociales, políticas o económicas que rodearon los hechos del caso" y la pretensión de que se conozca el contexto del caso presente, igualmente, "es improcedente".

A este respecto la Corte destaca, "que para resolver los distintos casos sometidos a su conocimiento, ha requerido tomar en cuenta el contexto, pues el entorno político e histórico es determinante para el establecimiento de las consecuencias jurídicas en el caso...".

Por esta razón, concluye con razón sobrada la Corte, "el análisis de la supuesta desaparición forzada del señor Radilla Pacheco no puede aislarse del medio en el que dichos hechos supuestamente ocurrieron, ni se puede determinar las consecuencias jurídicas respectivas en el vacio propio de la descontextualización..." (párrs. 115 y 116) (énfasis añadido).

\section{DETENCIÓN Y POSTERIOR DESAPARICIÓN}

E1 25 de agosto de 1974 Rosendo Radilla Pacheco de 60 años de edad y su hijo de 11 años, viajaban en un autobús desde Atoyac de Álvarez a Chilpancingo, Guerrero. El autobús fue detenido por segunda ocasión por un retén militar y en donde únicamente quedó detenido el señor Rosen-

enero de 2009, serie C, núm. 194, parr. 98. Consultar en García Ramírez, Sergio (coord.), op. cit., vol. VI.

La Corte Interamericana subraya que en el mismo sentido la Corte Europea de Derechos Humanos rechazó argumentos presentados por un Estado con objeto de no enviar información de un expediente penal que se encontraba abierto... El Tribunal Europeo consideró insuficiente alegar, inter alia, que la investigación criminal estaba pendiente y que el expediente contenía documentos clasificados como secretos. Cfr. Eur. C.L.H.R. Case of Imakayeva v. Russia Apllication no 7615/02. Judgment of 9/XL/06 parrs. 122 y 123. 
do Radilla Pacheco porque "componía corridos"; a lo que éste contestó que eso no constituía ningún delito, "..sin embargo un agente militar le respondió "mientras, ya te chingaste" (sic) (párrs. 124 y 125) (énfasis añadido).

En cuanto al "contexto" en el que ocurrieron los hechos del presente caso, ha sido documentado, subrayó la Corte, "que en la época en que fue detenido y hecho desaparecer el señor R. Radilla Pacheco, en diversas partes del territorio mexicano tuvieron lugar numerosas desapariciones forzadas de personas" (párr. 132).

Más adelante, la Corte Interamericana reitera que la figura de la desaparición forzada de personas "constituyó una violación múltiple de varios derechos protegidos por la Convención Americana que coloca a la víctima en estado de completa indefensión, acarreando otras vulneraciones conexas, siendo particularmente grave cuando forma parte de un patrón sistemático o práctica tolerada por un Estado". Y en seguida la Corte va a puntualizar algo de la mayor trascendencia: "La desaparición forzada, implica un craso abandono de los principios esenciales en que se fundamenta el Sistema Interamericano, y su prohibición ha alcanzado carácter de jus cogens" (párrs.138 y 139). ${ }^{7}$

Por lo anterior, y en conclusión sobre este punto, la Corte va a declarar

... que toda vez que haya motivos razonables para sospechar que una persona ha sido sometida a desaparición forzada, debe iniciarse una investigación. Esta obligación es independiente de que se presente una denuncia, pues en casos de desaparición forzada el derecho internacional y el deber general de garantía, imponen la obligación de investigar el caso ex officio, sin dilación, y de una manera seria, imparcial y efectiva (párr. 143).

7 Cfr. Caso Goiburú y otros vs. Paraguay, sentencia del 22 de septiembre de 2006, serie C, núm. 153 .

"En definitiva, la Corte estima que tal como se desprende del preámbulo de la Convención sobre Desaparición Forzada de Personas, ante la particular gravedad de estos delitos y la naturaleza de los derechos lesionados, la prohibición de la desaparición forzada de personas y el correlativo deber de investigarlas y sancionar a sus responsables la alcanzado el carácter de jus cogens" (párrafo 84). Véase en García Ramírez, Sergio (coord.), op. cit., vol. IV, p. 373.

Igualmente son varias las sentencias de cortes constitucionales de los Estados Americanos que han declarado categóricamente que el delito de desaparición forzada de personas se constituye como un delito: continuo, permanente, de lesa humanidad, imprescriptible y no amnistiable. Véase Caso Radilla Pacheco, cit., párr. 140, nota 127. 
Teniendo en cuenta la Corte, como suficientemente acreditado la detención arbitraria de Radilla Pacheco por militares del Ejército en un retén militar y trasladado al Cuartel Militar de Atoyac de Álvarez, Guerrero, la Corte va a señalar al Estado mexicano como responsable internacionalmente por la violación del derechos a la libertad e integridad personal y a la vida misma de Radilla Pacheco de conformidad con lo dispuesto por la Convención Interamericana sobre Desaparición Forzada de Personas (párr. 154). ${ }^{8}$

\section{DERECHOS DE ACCESO A LA JUSTICIA Y LA OBLIGACIÓN DE REALIZAR INVESTIGACIONES EFECTIVAS}

Tanto la Comisión Interamericana de Derechos Humanos como los mismos representantes de los familiares del señor Rosendo Radilla Pacheco alegaron en el proceso ante la Corte que si los familiares no habían interpuesto denuncia formal en el momento en que ocurrieron los hechos, no era por otra razón que la del contexto social y político imperante en la época — periodo de la llamada "guerra sucia"—, y por el muy fundado temor a represalias por parte de diversas autoridades estatales.

Con todo, hubo manifestaciones populares sobre lo acontecido; sin embargo el representante del Estado mexicano señaló que

8 La Corte Interamericana finca una responsabilidad internacional al Estado mexicano, concretamente de acuerdo al artículo I y al artículo XI de la CIDFP, las cuales asientan, inter alia, que "Los Estados Partes en esta Convención se comprometen a:

No practicar, no permitir, ni tolerar la desaparición forzada de personas, ni aún en estado de emergencia, excepción o suspensión de garantías individuales;

Sancionar en el ámbito de su jurisdicción a los autores, cómplices y encubridores del delito de desaparición forzada de personas así como la tentativa del mismo... (Art. I).

En cuanto al Artículo XI, éste estipula expresamente que: "Toda persona privada de libertad debe ser mantenida en lugares de detención oficialmente reconocidos y presentada sin demora, conforme a la legislación interna respectiva, a la autoridad judicial competente.

Los Estados partes establecerán y mantendrán registros oficiales actualizados sobre sus detenidos y... los pondrán a disposición de los familiares, jueces, abogados...".

Convención Interamericana sobre Desaparición Forzada de Personas, adoptada en Belém do Pará, Brasil, el 9 de julio de 1994, en el XXIV periodo ordinario de sesiones de la Asamblea General. Entrada en vigor, el 28 de marzo de 1996. México la suscribe el 4 de mayo de 2001 y la ratifica el 9 de abril de 2002 
... las manifestaciones populares... no constituían stricto sensu una forma reconocida de noticia criminis, por lo que insistió en que fue el 27 de marzo de 1992 cuando el Ministerio Público tuvo conocimiento formal de los hechos... Con base en lo anterior, el Estado señaló que los hechos fueron denunciados 18 años después, y que ese hecho no era imputable al Estado (párrs. 193-195).

Sin embargo, la contradicción palmaria en que incurre el representante del Estado mexicano no podía dejarla de advertir la Corte Interamericana, subrayándola de la manera siguiente: "Al respecto, el Tribunal constata que durante la audiencia pública el Estado manifestó que «el delito no fue atendido en su momento en gran medida por el contexto político y el marco institucional que... regían entonces»...".

En esta misma línea de razonamiento, uno en verdad, no llega a entender ¿cómo entonces puede pretender el representante del Estado, que las consecuencias que se derivan del retraso injustificado en el inicio de las investigaciones, puedan ser imputables a alguno de los familiares y no, como es patente, al Estado mismo como sujeto responsable de derecho internacional?

Y todavía sobre el mismo punto, va abundar más la misma Corte para no dejar duda alguna:

En casos de desaparición forzada de personas, la denuncia formal de los hechos no descansa exclusivamente en los familiares de las víctimas, sobre todo cuando es el propio aparato gubernamental el que lo obstaculiza. En el presente caso, es claro que fueron familiares del señor Radilla Pacheco quienes inicialmente, por sus propios medios, realizaron diversas acciones encaminadas a su búsqueda, a pesar de las dificultades propias del contexto político imperante (párr. 197, énfasis añadido).

\section{EL PRINCIPIO DE EFECTIVIDAD EN LAS INVESTIGACIONES}

La Corte fundamentándose en su propia jurisprudencia, es de la opinión,

que las autoridades encargadas de las investigaciones tenían el deber de asegurar que en el curso de las mismas se valoraran los patrones sistemáticos que permitieron la comisión de graves violaciones de los derechos humanos en el presente caso. En aras de garantizar su efectividad — añade 
la Corte - la investigación debió ser conducida tomando en cuenta la complejidad de este tipo de hechos y la estructura en la cual se ubican las personas probablemente involucradas en los mismos, de acuerdo al contexto en que ocurrieron... (párr. 206). ${ }^{9}$

Contrariamente a lo señalado, vehementemente, por los representantes del Estado, la Corte encuentra que las autoridades mexicanas han incurrido en negligencia y grave impunidad, ya que, entre otras cosas, a 35 años desde que fuera detenido y desaparecido el señor Rosendo Radilla Pacheco, y a 17 años desde que se presentó formalmente la denuncia penal (que es cuando el Estado alega haber tenido noticia por vez primera), no ha habido una investigación seria conducente tanto a determinar su paradero como a identificar, procesar y en su caso, sancionar a los responsables de tales hechos (párr. 214). ${ }^{10}$

\section{TIPIFICACIÓN DEL DELITO}

Los representantes del Estado mexicano hicieron notar que en el "supuesto de que fuera factible la aplicación del delito de desaparición forzada", cosa que ponían en duda, en todo caso existiría,

9 En el importante Caso de la Masacre de la Rochela vs. Colombia, en su etapa de fondo, reparaciones y costas de 2007, la Corte Interamericana, bajo la presidencia del juez Sergio García Ramírez, sostuvo con respecto a la efectiva y debida diligencia en las investigaciones que: “... La inefectividad de los procesos penales queda claramente evidenciada al analizar la falta de debida diligencia en la conducción de las acciones oficiales de investigación. Esta falta de debida diligencia se manifiesta en la irrazonabilidad del plazo transcurrido en las investigaciones..., las demoras, obstáculos y obstrucciones en la realización de actuaciones procesales y graves omisiones en el seguimiento de líneas lógicas de investigación”. Según la obligación de la debida diligencia, sigue diciendo la Corte, "el órgano que investiga una violación de derechos humanos debe utilizar todos los medios disponibles para llevar a cabo, dentro de un plazo razonable, todas aquellas actuaciones y averiguaciones que sean necesarias con el fin de intentar obtener el resultado que se persigue". Corte I.D.H. Caso de la Masacre de la Rochela, sentencia del 11 de mayo de 2007, Serie C, núm. 163, en García Ramírez Sergio, op. cit., vol. V, párrs. 194 y 195, pp. 225 y 226.

10 En el caso de la "Panel Blanca" (Paniagua Morales y otros) vs. Guatemala", la Corte definió la impunidad, como "la falta en su conjunto de investigación, persecución, captura, enjuiciamiento y condena de los responsables de las violaciones de los derechos protegidos por la Convención Americana”. op. cit., párrafo 173. 
un obstáculo insuperable consistente en que el tipo requiere que el activo del delito tenga el carácter de servidor público... siendo que en el presente caso el inculpado Francisco Quiroz Hermosillo pasó a situación de retiro, es decir, causó baja del servicio activo del Ejército Nacional Mexicano, a partir del 15 de junio de $2000 \ldots$; por lo que al momento de la entrada en vigor del tipo penal de desaparición forzada en el derecho punitivo federal mexicano (2001)... ya no tenía el carácter de servidor público (sic) (párr. 236).

Una vez más, no podemos dejar de mostrar nuestro gran azoro ante la réplica del Estado mexicano, en donde y de acuerdo con la misma, bastaba que el inculpado haya "pasado a situación de retiro" aproximadamente un año antes a la vigencia del tipo penal de "desaparición forzada" (artículo 215-A), ipara que automáticamente el inculpado, no pudiera ya tener tal carácter procedimental, y por ende, no pudiera ser procesado!

Por fortuna los señalamientos de los responsables del Estado llegan a ser tan endebles, que no le cuesta mayor trabajo a la Corte reiterar una y otra vez, que por tratarse la desaparición forzada de personas, de un delito de ejecución permanente, al entrar en vigor la tipificación del delito, "la nueva ley resulta aplicable por mantenerse en ejecución la conducta delictiva, sin que ello represente una aplicación retroactiva".

Por ello y en forma por demás categórica, la Corte subraya que “... es inadmisible el alegato del Estado... ya que mientras no se establezca el destino o paradero de la víctima, la desaparición forzada permanece invariable, independientemente de los cambios en el carácter de «servidor público» del autor" (párrs. 239-240 énfasis añadido).

Además la Corte va a considerar al Estado mexicano como responsable por haber incumplido los requerimientos del artículo 8.1 (Garantías Judiciales) de la Convención Americana porque, "En total han transcurrido 17 años desde que la autoridad ministerial tuvo formal conocimiento de la desaparición forzada del señor R. Radilla Pacheco, sin que el Estado haya válidamente justificado la razón de esta demora". El plazo que puede considerarse como razonable ha sido "sobrepasado excesivamente" (párrs. 244 y 245). ${ }^{11}$

11 En lo tocante al derecho a la participación en el proceso penal de la víctima y a la coadyuvancia en el mismo, conforme no sólo al derecho internacional, sino incluso al propio derecho positivo mexicano (artículo 20 apartado C, fracción II, de la Constitución Política), la Corte Interamericana encontró responsable al Estado mexicano por negar el 


\section{ACTUACIÓN EN LA JURISDICCIÓN MILITAR}

Del análisis de los hechos se desprende que el 27 de octubre de 2005, el primer Tribunal Colegiado en Materia Penal Administrativa resolvió que el Juzgado Primero Militar era competente para conocer de la causa en contra de Francisco Quiroz Hermosillo. Este Tribunal Colegiado, señaló que dicha persona se desempañaba como teniente coronel de infantería del ejército mexicano en la población de Atoyac, Guerrero, estando bajo su mando los retenes o puestos de revisión.

Este mismo Tribunal Colegiado resolvió que dado que el delito que probablemente había cometido el señor Quiroz Hermosillo era el de privación de la libertad, en su modalidad de plagio o secuestro, previsto y sancionado por el Código Penal vigente en la época, dicho delito era considerado como contrario a la disciplina militar (artículo 57, fracción III, Código de Justicia Militar, DOF, 31 de agosto de 1933), por lo que caía dentro de la jurisdicción militar el conocer y resolver en consecuencia. ${ }^{12}$

En forma reiterada, la Corte Interamericana ha destacado que la jurisdicción militar en un Estado democrático, ha presentado una franca tendencia a reducirse e incluso a desaparecer, por lo que en los casos de Estados que todavía la contemplen, esta debe ser utilizada cuando parezca estrictamente necesario y absolutamente siempre sustentada en los criterios, principios y garantías que gobiernan el derecho penal contemporáneo.

En un Estado democrático de derecho, la jurisdicción penal militar ha de tener un alcance restrictivo y excepcional y estar encaminada a la protección de intereses jurídicos especiales, vinculados a las funciones propias de las fuerzas militares. Por ello... en el fuero militar sólo se debe juzgar a

acceso al expediente, que es considerado, como dice la Corte "un requisito sine qua non de la intervención procesal de la víctima en la causa en la que se constituye como parte coadyuvante o querellante".

Por lo mismo, la Corte no admite en lo absoluto el alegato del agente mexicano en cuanto a que el Estado había "garantizado el pleno acceso de la coadyuvante Tita Radilla Martínez, por si o por conducto de sus representantes legales, al expediente que actualmente se integra..." (párrafo 252 y 255) (sic).

$12 C f r$. Sentencia del Primer Tribunal Colegiado en Materia Penal Administrativa del Vigésimo Primer Circuito en el Conflicto Competencial Penal 6/2005 de 27 de octubre de 2005; y Declaración rendida ante fedatario público (affidávit) por la Agente del Ministerio Público, Patricia Valadez Sanabria (expediente de fondo, tomo IV, folio 1, 431). 
militares activos por la comisión de delitos o faltas que por su propia naturaleza atenten contra bienes jurídicos propios del orden militar.

\section{Y la Corte va a añadir algo de capital importancia:}

Tomando en cuenta la naturaleza del crimen y el bien jurídico lesionado, la jurisdicción penal militar no es el fuero competente para investigar, y en su caso, juzgar y sancionar a los autores de violaciones de derechos humanos sino que el procesamiento de los responsables corresponde siempre a la justicia ordinaria... Cuando la justicia militar asume competencia sobre un asunto que debe conocer la justicia ordinaria, se ve afectado el derecho al juez natural, a fortiori, el debido proceso... Frente a situaciones que vulneren derechos humanos de civiles bajo ninguna circunstancia puede operar la jurisdicción militar (párrs. 272-274). ${ }^{13}$

Los agentes del Estado mexicano, alegaron que el "fuero de guerra" no implicaba un privilegio para los miembros de las fuerzas armadas sino una jurisdicción especializada, e hicieron hincapié en que las sentencias dictadas por tribunales militares eran susceptibles de ser revisadas por autoridades federales mediante la institución del "Amparo" por lo que se conservaba así la garantía del juez natural en los casos en que la víctima del delito fuese una persona civil (párrs. 268 y 269).

Sin embargó, la Corte Interamericana controvirtió dichos alegatos, destacando que todo proceso penal es considerado como si fuera uno solo a través de sus diversas instancias procesales, esto es, desde la co-

13 Cfr. En el Caso Palamara Iribarme vs. Chile, y actuando como presidente el juez Sergio García Ramírez, la Corte Estimó “que en las normas que definen la jurisdicción penal militar, en Chile no se limita el conocimiento de los tribunales militares a los delitos que por la naturaleza de los bienes jurídicos- penales castrenses protegidos son estrictamente militares y constituyen conductas graves cometidas por militares que atentan contra dichos bienes jurídicos".

Corte IDH, Caso Palamara vs. Chile, Fondo, Reparaciones y Costas, sentencia del 22 de noviembre de 2005, serie C, núm. 135. Véase García Ramírez, Sergio (coord.), op. cit., vol. III, pár. 132, p. 577.

Por otro lado el Comité de Derechos Humanos de Naciones Unidas en repetidas ocasiones ha hecho notar que el deber de investigar a fondo las presuntas violaciones de derechos humanos, en particular las desapariciones forzadas de personas... es aplicable a fortiori, en los casos en que los autores de esas violaciones han sido identificados". O.N.U. Comité de Derechos Humanos. Caso Arhuacos vs. Colombia, párrafo 8.8, 19 de agosto de 1997, CCPR/C/60/612/1995. 
rrespondiente a la primera instancia como a las ulteriores instancias procedimentales.

Por ello, siguió diciendo la Corte "En el presente caso, la sola posibilidad de que las decisiones emanadas de tribunales militares pueden ser «revisadas» por las autoridades federales no satisface el principio del juez natural, ya que desde la primera instancia el juez debe ser competente" (párrs. 280 y 281, énfasis añadido).

En conclusión de este punto, la Corte va a responsabilizar al Estado mexicano, ya que éste "vulneró el principio del juez natural al extralimitar la esfera de la justicia castrense... en contravención de los parámetros de excepcionalidad y restricción que caracterizan a la jurisdicción penal militar" (párr. 282). ${ }^{14}$

\section{LA ESFERA DE LA JUSTICIA CASTRENSE " VIS-À-VIS" \\ LA CONVENCIÓN INTERAMERICANA SOBRE DESAPARICIÓN FORZADA}

El Estado mexicano desde un principio y en el escrito final de alegatos había sostenido la incompetencia de la Corte Interamericana, para conocer sobre la supuesta nulidad de la "reserva" formulada por México al artículo XI de la Convención Interamericana sobre Desaparición Forzada de Personas (CIFP).

Sin embargo parecería que los representante del Estado desconocen el principio de derecho internacional consuetudinario según el cual las "reservas" formuladas por un Estado parte, "se integran al tratado mismo,

14 Por otro lado y durante el transcurso de la audiencia pública, el perito y profesor Miguel Sarre, advirtió sobre la extensión de la jurisdicción militar en México, en tanto que el secretario general adjunto de la Comisión Internacional de Juristas, Federico Andreu-Guzmán en la Declaración rendida ante la Corte, señaló además que, "mediante la figura del delito de función o con ocasión del servicio consagrado por el artículo 57 del Código de Justicia Militar, la jurisdicción mexicana tiene las características de un fuero personalizado a la condición de militar del justiciable y no a la naturaleza del delito". Cfr. Declaración rendida por el señor Federico Andreu-Guzmán ante fedatario público (affidávit) el 22 de junio de 2009. Expediente de fondo, tomo IV- folio I, 319.

Por último hay que subrayar que si el Juez Cuarto de lo Militar, dictó auto de sobreseimiento en el Caso del Teniente Coronel de Infantería, Sr. Francisco Quiroz Hermosillo fue simple y sencillamente en virtud de la extinción de la acción penal por muerte del imputado, quien falleció el 19 de noviembre de 2006. Cfr. Affidávit de la Agente del Ministerio Público de la Federación (testigo nombrado por el Estado) M. Patricia Valadez Sanabria, expediente de fondo, tomo IV, folio 1432. 
de tal manera que no es posible interpretarlo cabalmente, respecto del Estado reservante, sin interpretar la reserva misma".

En la jurisprudencia interamericana, el problema de las "reservas" planteado en el Caso de las Restricciones a la Pena de Muerte /OC-3/83 del (/IX/1983), había sido ya analizado por la Corte Interamericana de Derechos Humanos en 1982, en la Opinión Consultiva referente, precisamente, al "Efecto de la Reservas sobre la entrada en vigencia de la Convención Americana" (artículos 74 y 75) (OC-2/82 del 24 de septiembre de 1982).

Una vez que la Corte había abordado y resuelto las cuestiones preliminares relativas a la competencia de la misma, la Corte va a enfatizar el hecho de que la Convención Americana, si bien era un tratado multilateral, presentaba características muy especiales en virtud, fundamentalmente, de que en ésta última no existe un intercambio recíproco de derechos entre Estados, sino que "su objeto y fin", antes al contrario, consistía preponderantemente, en la específica protección de los derechos fundamentales de los seres humanos.

En este mismo sentido se había referido la Comisión Europea de Derechos Humanos cuando declaró (1961), que las obligaciones asumidas por las partes, eran esencialmente de carácter objetivo, diseñadas para la protección de los derechos humanos en contra de violaciones de los Estados, contratantes, en vez de crear derechos subjetivos entre las partes contratantes (Autriche v/s Italie. Req $\mathrm{N}^{\circ}$ 788/60 Annuaire C.E.D.H, vol. IV).

Por su parte la Corte Europea de Derechos Humanos, destacó categóricamente, que la Convención, "a diferencia de los tratados internacionales de naturaleza clásica... desborda el marco de la simple reciprocidad entre Estados contratantes. Por encima de una red de compromisos sinalgmáticos bilaterales, la Convención crea obligaciones objetivas que, en términos de su preámbulo, benefician de una «garantía colectiva»" (Irlande c/ Royaume-Uni, 18 janvier 1978, G.A. N 18).

En el famoso Caso Belilos c/Suiza (1988), baste decir para nuestros propósitos, que la Corte Europea, dictaminó que la "declaración con valor de reserva", formulada por Suiza era ilegal por ser contraria a la Convención (artículo 64), la cual se refería a las reservas que pueden formularse por los Estados, siempre y cuando éstas no sean "generales", El gobierno helvético argumentó ante la Corte Europea, que ésta no era competente para conocer y evaluar la legalidad o ilegalidad de una reserva, ya que ninguna objeción había sido formulada por ningún Estado parte en la Convención, e incluso, tampoco por el depositario. 
La Corte Europea, en forma lacónica, pero contundente, se limitó a responder que: "El silencio del depositario y de los Estados contratantes no priva a los órganos de la Convención de su facultad y poder de apreciación". ${ }^{15}$

\section{RESERVA DE MÉXICO}

La reserva concreta formulada por México al artículo IX de la Convención sobre Desaparición Forzada fue redactada en los siguientes términos:

El gobierno de los Estados Unidos Mexicanos al ratificar la Convención Interamericana sobre Desaparición Forzada de Personas, adoptada en la ciudad de Belém, Brasil el 9 de junio de 1994, formula expresa reserva al artículo IX, toda vez que la Constitución Política reconoce el fuero de guerra, cuando el militar haya cometido algún ilícito encontrándose en servicio. El fuero de guerra no constituye jurisdicción especial en el sentido de la Convención, toda vez que conforme al artículo 14 de la Constitución mexicana, nadie podrá ser privado de la vida, de la libertad o de sus propiedades, posesiones o derechos, sino ante juicio seguido ante los tribunales previamente establecidos, en el que se cumplan las formalidades esenciales del procedimiento y conforme a las leyes expedidas con anterioridad al hecho. ${ }^{16}$

Al analizar la Corte la "reserva mexicana" al artículo IX, y su compatibilidad con el "objeto y fin del tratado", ésta implica "referirse a un fuero que para ser aplicado requiere de una calificación personal, no material. No se manifiesta que sea necesario un análisis de los intereses jurídicos

15 Belilos c/ Suisse, 29 april 1988, serie A, núm. 1132, párrafo 47. La cuestión de saber se debía considerarse como "reserva" una "declaración calificada de interpretativa" aparecía en sumo grado difícil para la Corte, principalmente, porque en el caso concreto, el gobierno helvético había formulado en un solo y mismo instrumento de ratificación una serie de reservas, así como "declaraciones interpretativas".

Véase Gómez-Robledo, Alonso, Derechos Humanos..., cit., pp. 53-81. Véase CohenJonathan, Gérard, "Les réserves dans las traitès Esntitutionnels relatifs aux droits de 1'homme: nouveaux aspects européens et internationaux", Révue Générale- de Droit Internatione Public, t. 100/1996/4, pp. 915-949.

16 Véase Documentos Básicos en Materia de Derechos Humanos en el Sistema Interamericano, OEA, Washington, 2006. 
detrás del ilícito, ni se toma como punto de referencia la disciplina militar o cualquier otro objetivo jurídico castrense" (párr. 307).

Si la justicia militar es de naturaleza excepcional, como reiteradamente lo ha establecido la Corte, al añadir México la reserva al artículo IX de la CIDFP, el Estado está lisa y llanamente, estableciendo un régimen general sobre la competencia de la justicia castrense.

Igualmente, si uno de los principales derechos protegidos por la CIDFP, es el del "juez natural", indisolublemente vinculado al "derecho al debido proceso legal" y al de "acceso a la justicia" (artículos 8.1 y 25.1 de la $\mathrm{CADH}$ ), derechos éstos reconocidos como no-susceptibles de derogación, entonces México, en realidad no se está comprometiendo, como bien señala la Corte, “... a respetar el derecho a un juez competente para conocer de la causa penal en torno al delito de desaparición forzada, que es el juez común..." (párr. 309).

La Corte Interamericana de Justicia en la "Opinión Consultiva sobre la Convención sobre Prevención y Represión del Crimen de Genocidio", resolvió que

... Un Estado que ha formulado y mantenido una reserva que ha sido objetada por una o más partes en la Convención pero no por otras, puede ser considerado como Parte en la Convención si la reserva es compatible con el objeto y fin de la Convención; caso contrario dicho Estado no puede ser considerado como Parte en esa Convención (p. 15). ${ }^{17}$

Este mismo principio rector fue retomado por la Comisión de Derecho Internacional y así plasmado en la Convención de Viena de 1969 sobre Derecho de los Tratados: "Un Estado podrá formular una reserva en el momento de firmar, ratificar, aceptar o aprobar un tratado o de adherirse al mismo, a menos que:... c) la reserva sea incompatible con el objeto y fin del tratado" (artículo 19, inciso c). ${ }^{18}$

17 CIJ, Avis Consultatif, 28 mai 1951, Recueil 1951 p. 496. Los términos, "the object and purpose" o "l'objet et le but" que emplea la CIJ, se traducen a menudo como "objeto y propósito", o bien como "objeto y fin"

18 Véase Convención de Viena sobre Derecho de los Tratados de 23 de mayo de 1969; ratificada por México el 25/IX/1974, entrada en vigor, el 27 de enero de 1980.

Este verdadero Código de Derecho de los Tratados codifica en lo general (excepción hecha del precepto del articulo 53 sobre el iuscogens) las principales normas, principios y criterios del derecho consuetudinario sobre derecho de los tratados. Véase para una visión de conjunto de las deliberaciones llevadas a cabo por la Comisión de Derecho 
Respecto al punto preciso de las "reservas" en los tratados, la Corte Interamericana ha sostenido que: "Toda reserva destinada a permitir al Estado la suspensión de uno de los derechos fundamentales, cuya derogación está en toda hipótesis prohibida, debe ser considerada como incompatible con el objeto y fin de la Convención y, en consecuencia, no autorizada por ésta" y más adelante apuntaba: "La interpretación de las reservas debe tener en cuenta el objeto y fin del tratado, que en el caso de la Convención Americana, es la protección de los derechos fundamentales de los seres humanos, independientemente de su nacionalidad, tanto frente a su propio Estado, como frente a los otros Estados contratantes". ${ }^{19}$

Por todo lo anterior, la Corte Interamericana va a concluir que la investigación de la detención y posterior desaparición del señor Rosendo Radilla Pacheco,

no ha sido diligente, no ha sido asumida en su totalidad como un deber propio del Estado ni ha sido dirigida eficazmente tanto a la identificación, proceso y eventual sanción de todos los responsables, como a la determinación del paradero del señor Radilla Pacheco. Asimismo el Tribunal estima, que al extender la competencia del fuero castrense a delitos que no tienen estricta conexión con la disciplina militar..., el Estado ha vulnerado en derecho a un juez natural de los familiares... quienes tampoco dispusieron de un recurso que les permitiera impugnar el juzgamiento de la detención y posterior desaparición... (párr. 313). ${ }^{20}$

Internacional, puede consultarse: Conférence des Nations Unies sur le Droit des Traites Comptes Rendius analytiques. Documents Officiels. A/CONF. 39/11, New York 1969.

19 Véase Opinión Consultiva "Efecto de las Reservas (...) “OC-2/82. 24/IX/82, serie A, núm. 2, párr. 29-35. Ver Opinión Consultiva, "Restricciones a la Pena de Muerte”. OC3/83, serie A, núm. 3, párr. 61 y 65, en Gómez-Robledo V., Alonso, Derechos humanos en el sistema interamericano, cit., pp. 53-81. El efecto de las reservas sobre la entrada en vigencia de la Convención Americana sobre Derechos Humanos.

20 En particular la Corte Interamericana encontró que la "reserva" formulada por México al artículo IX de la C.I.D.F.P, implicaba el desconocimiento del derecho humano al "juez natural “, además de que no satisfacía el requisito establecido en el artículo XIX de la propia C.I.D.F.P, i. e., que las reservas formuladas por los Estados, no pueden ser en ningún caso, incompatibles con el "objeto y propósito de la Convención", y por tanto se declaraba como una reserva inválida de pleno derecho, párrs. 311 y 312. Cfr. "Resolución sobre las personas desaparecidas y la asistencia a sus familiares "aprobada por la Asamblea General de la O.E.A el 4 de junio de 2009. AG/RES.2513 XXXIX-0/09. 


\section{TIPIFICACIÓN DEL DELITO DE DESAPARICIÓN FORZADA DE PERSONAS}

La Convención Interamericana sobre Desaparición de Personas de 1996 (vigente para México desde el 9 de abril de 2002) en su artículo II, dispone:

Para los efectos de la presente Convención, se considera desaparición forzada la privación de la libertad a una o más personas, cualquiera que fuere su forma, cometidas por agentes del Estado o por personas o grupo de personas que actúen con la autorización, el apoyo o la aquiescencia del Estado, seguida de la falta de información o de la negativa a reconocer dicha privación de la libertad o de informar sobre el paradero de la persona, con lo cual se impide el ejercicio de los recursos legales y de las garantías procesales pertinentes.

Por su parte México no contemplaría el crimen de "desaparición forzada", sino hasta 2001 en su Código Penal Federal (CPF), pero sin que exista coincidencia con varios puntos de la Convención Interamericana.

En el artículo 215-A, en el capítulo III bis de nuestro CPF, se estipula lo siguiente:

Comete el delito de desaparición forzada de personas, el servidor público que, independientemente de que haya participado en la detención legal o ilegal de una o varias personas, propicie o mantenga dolosomante su ocultamiento bajo cualquier forma de detención.

Es precisamente por esta falta de correlación entre el dispositivo internacional y el dispositivo interior, que los representantes de los familiares sostuvieron que el caso del señor Rosendo Radilla Pacheco, permanecía "en total impunidad".

A lo anterior los representantes de México alegaron que si bien "entendían y compartían" (sic) la inquietud de los familiares, sin embargo, se había demostrado que en México, "existían leyes vigentes y efectivas que servían para impartir justicia, en los asuntos de toda índole, incluidos, por supuesto, los penales".

Ello se corroboraba aún más con la tipificación del delito en cuestión en el Código Penal Federal, desde el 1o. de junio de 2001, por lo cual no podría haber lugar a una eventual condena por violaciones al artículo II de la Convención (párr. 315). 
Contrariamente a lo alegado por los agentes mexicanos, la Corte indicó que la preceptiva mexicana del artículo 215-A, restringía la autoría del delito a "servidores públicos", y por ende, el tipo penal de desaparición forzada, presentaba un serio obstáculo para garantizar la sanción de "todos los autores, cómplices y encubridores", provenientes de "cualquiera de los poderes u órganos del Estado" (artículo I, CIDFP).

Asimismo, la Corte apuntó que la desaparición forzada de personas se caracterizaba por la negativa de reconocer la privación de libertad sobre el paradero de las personas (independiente que tampoco hace referencia a personas que actúan con apoyo o aquiescencia del Estado) y que éstos eran elementos consustanciales a la debida tipificación del delito. En una palabra, no se satisfacían en forma alguna los "elementos mínimos de la correcta tipificación del delito".

De lo anterior puede verse con claridad la fundamental falta de concordancia entre la norma jurídica internacional y la norma interna, lo cual resulta en una violación de México al derecho internacional, tanto convencional como consuetudinario, pues es un principio general de derecho, que todo Estado debe realizar las adecuaciones legislativas, administrativas o de cualquier otra índole, cuando ello sea necesario a fin de adecuar su derecho interno a las normas jurídico-internacionales (artículo I, inciso $d$, de la CIDFP). ${ }^{21}$

\section{CONCLUSIONES}

La Corte Interamericana de Derechos Humanos va a dar por fundado y motivado, que la desaparición forzada del señor Rosendo Radilla Pacheco aconteció en el "marco de un contexto de desapariciones forzadas de personas", y dictaminó en consecuencia, que las indagatorias e investigaciones deberían garantizar que en el curso de las mismas se valorasen, "los patrones sistemáticos que permitieron la comisión de graves violaciones de los derechos humanos... evitando omisiones en la recaudación

21 Curiosamente, la Corte Interamericana no parece hacer mención al gran elemento del "dolo" inserto en el artículo 215-A del Código Penal Federal, y ausente por completo en la tipificación internacional con lo cual se desvirtúa aún más, el delito de desaparición forzada de personas, pues en el Artículo II de la Convención Interamericana, no existe alusión de ninguna especie a la conciencia de la internacionalidad de la criminalidad del acto. Véase Huet, A- Koering- Joulin, R., Droit pénal international, París, Thémis, P.U.F., 2001, pp. 27-77. 
de pruebas y en el seguimiento de líneas lógicas de investigación" (párr. 333).

Por lo que respecta a los tribunales y las prácticas judiciales, la Corte subraya la obligación que tiene todo Estado - en este caso México-, en toda hipótesis en la cual ha ratificado un tratado internacional, como es el caso de la Convención Americana y otros instrumentos de derechos humanos, de que sus jueces supervisen los efectos de las disposiciones mencionadas a fin de que, "no se vean mermadas por aplicación de leyes contrarias a su objeto y fin, que desde un inicio carecen de efectos jurídicos. En otras palabras, el Poder Judicial debe ejercer un «control de convencionalidad» ex officio entre las normas internas y la Convención Americana..." (párr. 339).

En cuanto a la reparación debida por el Estado mexicano, y no pudiendo darse la restitutio in integrum esto es, el restablecimiento del statu quo ante, la Corte Interamericana dictará los montos de la indemnización correspondiente al daño emergente y el lucro usante (dammun emergens y lucrum cessans), así como el pago de una compensación en equidad por el "daño inmaterial" generado a raíz de las violaciones cometidas, sufrimiento causado a las víctimas y tratamiento recibido (parrs. 360 a 375).

De esta suerte la Corte Interamericana en su sentencia del 23 de noviembre de 2009 (infra) imputará al Estado mexicano una responsabilidad internacional por violación, inter alia, de los derechos a la libertad personal, a la integridad, al reconocimiento de la personalidad jurídica y a la vida, de conformidad con la Convención Americana sobre Derechos Humanos, y por la violación de los derechos a las garantías judiciales y a la protección judicial, reconocidos en la misma Convención Americana sobre Desaparición Forzada de Personas.

Ahora bien y analizando otros aspectos del crimen de desaparición forzada de personas, la misma Corte Interamericana de Derechos Humanos, desde su ya célebre Caso Velásquez Rodríguez de julio de 1988, sostuvo con toda claridad que: "El contexto en que se produjo la desaparición y la circunstancia de que siete años (sic) después continúe ignorándose que ha sido de él, son de por sí suficientes para concluir razonablemente que Manfredo Velásquez fue privado de su vida". ${ }^{22}$ 
A partir de esta sentencia del 29 de julio de 1988, la Corte Interamericana inaugura e instala la trascendental concepción de la presunción jurídica del fallecimiento.

En el Caso Bámaca Velásquez vs. Guatemala, la Corte en la etapa de fondo, señaló: "En el presente caso, por las circunstancias en que ocurrió la detención de Bámaca Velásquez a manos de agentes del Estado... y el transcurso de 8 años y 8 meses desde que fue capturado sin que se haya vuelto a tener noticias de él, hacen presumir al Tribunal que Bámaca Velásquez fue ejecutado" (párr. 173). ${ }^{23}$

Por último, en el Caso Castillo Páez vs. Perú, en donde el señor Ernesto Rafael Castillo Páez, estudiante universitario y profesor de 22 años de edad, había sido detenido por agentes de la Policía General, integrantes de la policía Nacional, en la ciudad de Lima, Perú, la Corte Interamericana reafirmaría el criterio de la presunción de deceso, añadiendo que el argumento que consiste en afirmar que sin cadáver no existe crimen, resulta totalmente inadmisible, ya que bastaría que los autores del crimen, ocultaran o destruyeran los cuerpos, para obtener así una absoluta impunidad. ${ }^{24}$

Así pues, si en casos en donde la desaparición forzada de personas en los cuales han transcurrido ocho o menos años desde su desaparición se actualiza la presunción de fallecimiento, en el caso sub iudice en donde habían transcurrido más de 33 años de los hechos, la presunción iuris et de iure de su muerte, es irrefutable. Lo que la Corte Interamericana ha establecido, con razón sobrada, es eximir a los familiares de la víctima, de la obligación de desahogar pruebas concretas del deceso de la persona en cuestión.

Todo este desarrollo pretorionano en el continente americano, parece haber tenido una influencia directa en la Corte de Derechos Humanos del Estrasburgo, asentando igualmente la presunción del deceso, apoyándose concretamente ésta última, en el hecho de que la persona en el momento

23 CIDH, Caso Bámaca Velásquez, sentencia del 25 de noviembre de 2000, serie C, núm. 70. En este caso fungía como presidente el doctor Antonio A. Cancado Trindade, hoy juez de la Corte Internacional de Justicia. Véase García Ramírez, Sergio, op . cit.,vol. I, pp. 464-498. En esta misma Sentencia se dice: “....si bien el Estado tiene el derecho y la obligación de garantizar su seguridad y mantener el orden público, su poder no es ilimitado..., idem, párr. 174.

24 CIDH, Caso Castillo Páez, sentencia del 3 de noviembre de 1997, serie C, resoluciones y sentencias núm. 34, párrafo 73. 
de la desaparición estaba "detenida", aunado al "largo periodo" que había transcurrido desde la detención misma y al hecho de que las autoridades habrían tenido alguna especie de "queja" en contra de la persona en cuestión (Caso Timurtas vs. Turquía. Arret du juin 2000. Cour. Europeénne, párrs. 83-86).

La Corte Interamericana de Derechos Humanos ha dejado claramente establecido en su jurisprudencia sobre casos de desaparición forzada de personas, que por tratarse de un grave hecho delictivo que genera una violación múltiple y continuada de derechos humanos fundamentales, acarreando otros delitos conexos — complejamente interconectados-, se trata del género de crimina juris gentium, habiendo alcanzado la jerarquía especial de norma de ius cogens. ${ }^{25}$

Si el contenido de la obligación que ha sido violada es considerada como esencial para la salvaguarda de los intereses fundamentales de la comunidad internacional, entonces — de acuerdo a la Comisión de Derecho Internacional (artículo 19.2) - ese hecho ilícito de particular "gravedad", será caracterizado como "crimen internacional".

Pero también es cierto, que la misma Comisión de Derecho Internacional, ha señalado que no sería correcto concluir en forma categórica y sin más taxativas, que toda violación de una obligación que emane de una "norma imperativa" constituye un "crimen internacional", y ello fundamentalmente, porque una norma de ius cogens, es independiente del proceso por el cual se reconocen ciertos hechos ilícitos de especial gravedad, como entrando dentro de la categoría de "crímenes internacionales".

El relator especial, el profesor Roberto Ago, puntualizó en diversas formas y en distintas sesiones de la Comisión de Derecho Internacional, lo siguiente:

... On irait en tout cas trop loin en disant qu' un crime international est la violation d' une rĕgle impérative de droit international. It faut être plus restrictif, car la notion de crime international et celle de rĕgle impérative sont deux notions qui émanent du même principe, mais qui ne coïncident pas entièrement. C' est seulement la violation de certaines rĕgles impératives, qui peut-être considérée comme un crime international. ${ }^{26}$

$25 C f r$. Goiburú y otros vs. Paraguay, sentencia sobre fondo, reparaciones y costas, del 22 de septiembre de 2006, serie C, núm. 153, párrs. 79 a 85.

26 Véase Annuaire de la Commission de Droit International Compte rendus analytiques, A/CN. 4/SER.A/1976, p. 75, párr. 13. 


\section{ANEXO \\ PUNTOS RESOLUTIVOS}

Por tanto,

\section{LA CORTE}

\section{DECIDE,}

Por unaminidad

Rechazar las excepciones preliminares interpuestas por los Estados Unidos Mexicanos, de conformidad con los párrafos 14 a 50 de la presente Sentencia.

Aceptar el reconocimiento parcial de responsabilidad internacional efectuado por el Estado, en los términos de los párrafos 52 a 66 de la presente Sentencia.

\section{DECLARA,}

Por unamidad, que,

El Estado es responsable de violación de los derechos de libertad personal, a la integridad personal, al reconocimiento de la personalidad jurídica y a la vida, consagrados en los artículos 7.1, 5.1, 5.2, 3 y 4.1 de la Convención Americana sobre Derechos Humanos, en relación con la obligación de respetar y garantizar contenida en el artículo 1.1 de la misma y con los artículos I y XI de la Convención Interamericana sobre Desaparición Forzada de Personas, en perjuicio del señor Rosendo Radilla Pacheco, en los términos de los párrafos 120 a 159 de la presente Sentencia.

El Estado es responsable por la violación del derecho a la integridad personal consagrado en los artículos 5.1 y 5.2 de la Convención Americana sobre Derechos Humanos, en relación con el artículo 1.1 de la misma, en perjuicio de las señoras Tita y Andrea, y del señor Rosendo, todos de apellidos Radilla Martínez, en los términos de los párrafos 160 a 172 de la presente Sentencia.

El Estado es responsable por la violación de los derechos a las garantías judiciales y a la protección judicial, reconocidos en los artículos 8.1 y 25.1 de la Convención Americana sobre Derechos Humanos, en relación con los artículos 1.1 y 2 de la misma y los artículos I incisos a), b) y d), IX y XIX de la Convención Interamericana sobre Desaparición Forzada de Personas, en perjuicio de las señoras Tita y Andrea, y del señor Rosendo, 
todos de apellidos Radilla Martínez, en los términos de los párrafos de 173 a 314 de la presente Sentencia.

El Estado incumplió el deber de adoptar disposiciones de derecho interno establecido en el artículo 2 de la Convención Americana sobre Derechos Humanos, en relación con los artículos I y III de la Convención Interamericana sobre Desaparición Forzada de Personas, respecto de la tipificación del delito de desaparición forzada de personas, en los términos de los párrafos 315 a 324 de la presente Sentencia.

\section{Y, DISPONE,}

Por unaminidad, que,

Esta Sentencia constituye per se una forma de reparación

El Estado deberá conducir eficazmente, con la debida diligencia y dentro de un plazo razonable la investigación y, en su caso, los procesos penales que tramiten en relación con la detención y posterior desaparición forzada del señor Rosendo Radilla Pacheco, para determinar las correspondientes responsabilidades penales y aplicar efectivamente las sanciones y consecuencias que la ley prevea, en los términos de los párrafos 329 a 334 de la presente Sentencia.

El Estado deberá continuar con la búsqueda efectiva y la localización inmediata del señor Rosendo Radilla Pacheco o, en su caso, de sus restos mortales, en los términos de los párrafos 335 a 336 de la presente Sentencia.

El Estado deberá adoptar, en un plazo razonable, las reformas legislativas pertinentes para compatibilizar al artículo 57 del Código de Justicia Militar con los estándares internacionales en la materia y de la Convención Americana sobre Derechos Humanos, en los términos de los párrafos 337 a 342 de la presente Sentencia.

El Estado deberá adoptar, en un plazo razonable, las reformas legislativas pertinentes para compatibilizar el artículo 215 A del Código Penal Federal con los estándares internacionales en materia y de la Convención Interamericana sobre Desaparición Forzada de Personas, en los términos de los párrafos 343 a 344 de la presente Sentencia.

El Estado deberá implementar, en un plazo razonable y con la respectiva disposición presupuestaria, programas o cursos permanentes relativos al análisis de la jurisprudencia del Sistema Interamericano de Protección de los Derechos Humanos en relación con los límites de la jurisdicción penal militar, así como un programa de formación sobre la debida investigación 
y juzgamiento de hechos constitutivos de desaparición forzada de personas, en los términos de los párrafos 345 a 348 de la presente Sentencia.

El Estado deberá publicar en el Diario Oficial de la Federación y en otro diario de amplia circulación nacional, por una sola vez, los párrafos 1 a 7, 52 a 66, 114 a 358 de la presente Sentencia, sin las notas al pie de página, y la parte resolutiva de la misma, y publicar íntegramente este Fallo en el sitio web oficial de la Procuraduría General de la Republica, en un plazo de seis meses, respectivamente, a partir de la notificación de este Fallo, en los términos de los párrafos 349 a 350 del mismo.

El Estado deberá realizar un acto público de reconocimiento de responsabilidad en relación con los hechos del presente caso y en desagravio a la memoria del señor Rosendo Radilla Pacheco, en los términos de los párrafos 351 a 354 de la presente Sentencia.

El Estado deberá realizar una semblanza de la vida del señor Rosendo Radilla Pacheco, en los términos de los párrafos 355 a 356 de la presente Sentencia.

El Estado deberá brindar atención psicológica y/o psiquiátrica y de forma inmediata, adecuada y efectiva, a través de sus instituciones públicas de salud especializadas, a las víctimas declaras en el presente Fallo que así lo soliciten, en los términos de los párrafos 357 a 358 del mismo.

El Estado deberá pagar las cantidades fijadas en los párrafos 365, 370, 375 y 385 de la presente Sentencia, por concepto de indemnización por daño material e inmaterial, y el reintegro de costas y gastos, según corresponda, dentro del plazo de un año, contado a partir de la notificación de presente Fallo, en los términos de los párrafos 360 a 392 del mimo.

La Corte supervisará el cumplimiento íntegro de esta Sentencia, en ejercicio de sus atribuciones y en cumplimiento de sus deberes conforme a la Convención Americana, y dará por concluìdo el presente caso una vez que el Estado haya dado cabal cumplimiento a lo dispuesto en la misma. El Estado deberá dentro del plazo de un año contado a partir de la notificación de esta Sentencia, rendir al Tribunal un informe sobre las medidas adoptadas para cumplir con la misma.

Redactada en español e inglés, haciendo fe el texto en español, en San José, Costa Rica, el 23 de noviembre de 2009. 


\section{DiCCIONARIO CABANELLES DE TORRES}

Sana Crítica.- El juez forma su convicción de acuerdo a la "sana critica", No tienen el deber de expresar en la sentencia "la valoración" de todas las pruebas producidas, sino únicamente los que fueren decisivas para el fallo de la causa.

No confundir c/la prueba tasada (legal), ni con la "libre convicción". El juez puede independizarse de la declaración testimonial sólo fundado en el error contenido en ella, (por lo que no es libre de convicción).

Prueba indiciaria.- La fundada en indicios. Esta prueba está implícita en el sistema de la sana crítica, que es el criterio rector (junto con las presunciones)

En la práctica, las "presunciones" y los "indicios", son tratados conjuntamente como si fuesen una y la misma cosa.

Presunciones.- "iuris et de iure", cuando no admiten prueba en contrario, y "iuris tantum", cuando sí la admiten.

Para parte de la doctrina la "presunción" surge del "indicio"

Incidentes.- Incidente "de previo y especial pronunciamiento", impide la prosecución del juicio principal, y se debe substanciar en la misma pieza de autos. Los demás incidentes se substancian por cuerda separada, sin suspender el curso de lo principal.

Affidávit.- no tiene significado muy claro. En general es una declaración jurada que se presta ante un funcionario dotado de fe pública. 